\section{EMBRYRIDDLE}

Aeronautical University

SCHOLARLY COMMONS
Journal of Aviation/Aerospace

Education \& Research

Volume 19

Number 1 JAAER Fall 2009

Article 1

Fall 2009

\title{
A Study on Factors Influencing the Performance of Airport Security and on Responsibility Assignment of Security Task at International Airports
}

Kwang Eui Yoo

Follow this and additional works at: https://commons.erau.edu/jaaer

\section{Scholarly Commons Citation}

Yoo, K. E. (2009). A Study on Factors Influencing the Performance of Airport Security and on Responsibility Assignment of Security Task at International Airports. Journal of Aviation/Aerospace Education \& Research, 19(1). https://doi.org/10.15394/jaaer.2009.1377

This Article is brought to you for free and open access by the Journals at Scholarly Commons. It has been accepted for inclusion in Journal of Aviation/Aerospace Education \& Research by an authorized administrator of Scholarly Commons. For more information, please contact commons@erau.edu. 


\title{
A STUDY ON FACTORS INFLUENCING THE PERFORMANCE OF AIRPORT SECURITY AND ON RESPONSIBILITY ASSIGNMENT OF SECURITY TASK AT INTERNATIONAL AIRPORTS
}

\author{
Kwang Eui Yoo.
}

\begin{abstract}
There are four major parties responsible for aviation security activities at an airport: the government department responsible for civil aviation, the police, the airport operator, and aircraft operators who have contracts with security companies. There are also several categories of security tasks at airports such as passenger security screening, checked baggage security control, access control to restricted areas, cargo and mail security, and crisis management. This paper discusses the assignment of responsibility for each security task to each entity involved in the aforementioned security activities. It analyzes the factors that influence the job performance of each security task, and then selects the best entity for each task. Data was gathered through an opinion survey given to experienced security practitioners at the research location and then examined with an AHP analysis in order to assess the relative importance of factors that influence security tasks and to decide the proper entity for each task.
\end{abstract}

\section{Introduction}

Since the attacks of $9 / 11$, many countries have strengthened their aviation security systems by either establishing new dedicated security organizations or changing some aspects of their existing security organization structures. It is thus easy to say that establishing a sole organization with a clear command chain for normal conditions as well as crisis situations is the best way to address the problems associated with the organizational structure of aviation security. However, it is not easy to create a single organization with absolute authority that is responsible for overseeing all the security functions at an airport due to the complexity of airport communities in which various organizations hold various responsibilities.

It is generally recognized that the major parties responsible for aviation security activities at an airport are the civil aviation authority within the government structure, the police, the airport operator, and the aircraft operators who have contracts with security companies. Further, there are several categories of security tasks at airports such as passenger security screening, checked baggage security control, access control to restricted areas, and cargo and mail security. Thus it is necessary to define and allocate the responsibility for each security task to the proper airport security organization in order to improve airport security. Therefore, this study discusses the assignment of responsibility for each security task to each entity involved in security activities in order to improve the performance of overall security activities at airports.

At first, the present study analyzes factors that influence the job performance required for each security task and then selects the best entity for that task considering factors identified as important. The required data is gathered through an opinion survey given to security practitioners at the research location and then examined with an AHP analysis in order to assess the relative importance of factors that influence security tasks and to decide the proper organization for each task. This research will contribute to solving the problems associated with improving aviation security performance at international airports.

The research location is South Korea's Incheon International Airport, at which data is gathered by surveying the opinions of aviation security practitioners, including security supervisors as well as security personnel who have more than three years work experience at the airport. 


\section{Review of Literature and Cases of Aviation Security Responsibility Assignment \\ Literature review}

Annex 17 of the Convention on International Civil Aviation is basic and essential regulatory literature for international aviation security because the security standards stated therein have to be implemented by every ICAO member country. Article 3.1.5 of Annex 17 states, "each contracting state shall require the appropriate authority to define and allocate tasks and coordinate activities between the departments, agencies and other organizations of the State, airport and aircraft operators and other entities concerned with or responsible for the implementation of various aspects of the national civil aviation security program." This standard expresses the idea that though the ultimate responsibility for aviation security belongs to the government, airport and aircraft operators, as well as other entities, may be responsible for implementing various security tasks. For example, under the Aviation Safety and Security Act, which has been in effect since August 2002 (Korean MOCT, 2002), the Korean government demands that the airport operator take responsibility for the security screening of all air passengers. According to the Act, the overall quality control of airport security performance is the government's responsibility.

Yoo and Lee (2004) studied the responsibility structure of security tasks at international airports in several countries and compared the advantages and disadvantages of each system. They pointed out that systems emphasizing a governmental role, like those in the USA, have better security performance, while systems that place the responsibility for security tasks on the airport operator have an advantage in maintaining the efficiency of overall airport operations. Askew (2004) researched the responsibility of passenger screening and argued that significant improvements in security screening outcomes and check point performance result from the implementation of the following principles: (1) A comprehensive recruitment program, (2) A comprehensive initial training program, (3) A regular recurrent training program, (4) Constant review and amendments of processes and procedures where necessary, (5) State of the art equipment, (6) A properly designed checkpoint, (7) High quality management and supervision, and (8) Accountability.

Feng (2003) also reviewed the aviation security structures in various countries such as the USA, Canada, the UK, Australia, New Zealand, Singapore, and Japan. He studied the organizational structure of national level aviation security and pointed out that only the US government created post $9 / 11$ a new national organization (i.e. the Transportation Security Administration) charged with overseeing transportation security under the Department of Homeland Security, while the other countries have security organizations under their respective Ministries of Transport. Based on the literature mentioned above as well as other relevant literature, the present study briefly introduces several examples of the responsibility structure of airport security activities in some countries.

Responsibility for Airport Security in the USA

Before $9 / 11$, the aircraft operator was mainly responsible for passenger and baggage screening at major airports. After 9/11, however, the US government established a new governmental organization called TSA (Transportation Security Administration) that deals with passenger and baggage screening, and is also tasked with analyzing threats that pertain to the entire transportation infrastructure. Because all screeners and their supervisors are government employees, it is possible that screening quality improved compared to that performed by private screeners. However, this system has some severe disadvantages. If there is no close cooperation between airport management and TSA, tightened screening procedures without consideration for overall airport operations may cause delays and congestion in traffic handling at airport passenger terminals. Major airports in the USA have a TSA security director who has an overall coordination function with airport managers for security issues. The TSA deals with the screening function only at screening checkpoints (SCP), and the airport police have law enforcement power. They will take over any criminal situations from TSA employees at SCP.

\section{Responsibility Structure for Airport Security in}

\section{European Countries}

In the UK, airport operators are responsible for all security activities at their own airports, and they usually employ subsidiary security companies to perform screening and access control at the airport. However, the airport security forces have a limited ability to function as a legal police force. Thus security personnel must turn criminals over to the police when they encounter criminal activity because it is the police at each airport who have all the legal power to arrest criminals.

In Switzerland as well, the airport authority manages all security-related responsibilities. However, the airport authority outsources passenger and baggage screening services to the national police, who are contracted to perform screenings with the power of law enforcement. In Germany, the government conducted security tasks, including passenger screening, and were responsible for all security activities at airports until the $1990 \mathrm{~s}$. In the mid1990s, however, Germany privatized passenger screening tasks in order to increase the efficiency of the process. Nonetheless, the ultimate responsibility for and supervision of passenger screening remained with the government.

By comparison, one remarkable point of the UK airport security system is that it stresses fluent airport operations by giving security responsibilities to the airport authority, while 
the German system puts more emphasis on governmental responsibility, and the Swiss system gives the authority for passenger security screenings to the national police.

\section{Structure of Responsibility for Airport Security in} Asian Countries

Japan is currently running an airline-dominant security system, much like the US system before $9 / 11$. Under this system, airlines' participation in screening their passengers potentially keeps certain responsibilities transparent; for example, liabilities related to security incidents during flight. In addition, the passenger information obtained through airlines' CRS (Computer Reservation System) can be effectively utilized for security purposes during the screening process. However, there is also the high possibility that screenings will be of poor quality due to airlines' cost saving measures and fast processing.

Hong Kong has a very desirable system in terms of having a clear chain of command. There, the Hong Kong airport authority is responsible for all airport security, and a subsidiary company named AVSECO performs all security functions including screening, permit issuing, access control, and so forth. In Singapore, the airport authority is responsible for access control, and the airport police have passenger and baggage screening responsibilities. However, screening services in Singapore are provided by a contracted private security company whose expenses are paid by the airport authority. As a result, the response of law enforcement at screening points in Singapore is quick and effective. However, one concern is that airport operations may be disturbed by unreasonable security measures without effective coordination between airport management and the police department.

\section{Responsibility Structure for Security Tasks in Korean} Airports

In accordance with the ICAO standards stated earlier, the Korean government is responsible for all security activities at Korean airports. The government has designated the Ministry of Construction and Transportation (MOCT) as ultimately responsible for aviation security, and the MOCT delegates responsibility to the Civil Aviation Safety Administration (CASA) in order to establish and practically implement civil aviation safety and security measures. The MOCT defines and allocates security tasks to each participant involved with aviation security activities, such as airport operators and airlines, and arranges coordination of the activities between organizations.

The system of responsibility for aviation security at Korean airports has changed dramatically in response to the $9 / 11$ incident. Before $9 / 11$, airlines had complete responsibility for passenger and baggage screening for their own passengers. After $9 / 11$, however, the airport authority took over all of the responsibilities concerned with screening passengers and their baggage in accordance with the "Act on
Aviation Safety and Security", the newly established regulation for aviation security. The airport authority fulfills its responsibility by contracting out the screening and access controlling tasks to specialized security companies, and the airport authority supervises the screening checkpoints by appointing a security supervisor from its own security unit to oversee passenger and baggage screening processes. Under the old regulations, which were effective until new regulation, passenger screening was supervised by the police.

The airport is also responsible for controlling access to restricted areas, a task that includes issuing and controlling permits. The airlines, however, are responsible for cargo screening, baggage protection, and aircraft security at the airport and during flight. The airlines are also responsible for security measures associated with catering and related services, and all other items loaded onto the aircraft for flight operation. However, the airlines hire specialized security companies for cargo screening and other security activities such as guarding aircraft parked areas, cargo areas, and areas for baggage make-up and storage. The security measures during flight are mainly fulfilled by the airlines' own crew members, including the flight crew and cabin crews, who have been trained for appropriate security tasks. The contracted security companies provide security services at the airport under the supervision of the client organization, namely the airport or airlines.

Taking a look at the government's responsibility, the quality control of security tasks at airports is overseen by CASA, and airport police cooperate with the airport authority when unlawful interference occurs in the airport complex. Close communication is formed between the police, the National Intelligence Services, airport operators, and airliners through the activities of the airport security committee.

\section{Research Methodology}

A study on airport security tasks and factors influencing the performance thereof is conducted in order to assess the assignment of responsibility for each security task at international airports. The research analyzes the opinions of those associated with airport security tasks and the factors influencing the performance thereof in terms of the assignment of responsibility for each security task at international airports. A questionnaire was administered in order to gather data from experienced airport security staff and supervisors working at the airport, and the gathered data was analyzed using the Analytic Hierarchy Process (AHP) methodology in order to formulate a model. The AHP method developed by Saaty $(1977 ; 1980 ; 1990)$ is a mathematical method for analyzing complex decisions, and aimed at integrating different measures into a single overall score for ranking alternative decisions, utilizing data gathered through surveys based on pairwise comparison judgments. It has been used extensively for the analysis of 
complex multi-attribute problems (Varis, 1989), and similar to many other multi-criteria analyses, it aggregates separate performance indicators into integrated performance indicators (Bouma et al, 2000).

In order to apply the AHP method, a hierarchical decision schema is constructed by decomposing the decision problem into its decision elements, after which the importance or preferences of the decision elements are examined in a pairwise comparison to the elements in the hierarchy. The parameters are estimated by carrying out pair-wise comparisons between the importance of the attributes or decision elements in the function using data made by each respondent. Comparisons are then made based on which of the two attributes in question are more important and by how much. The following explanation outlines the steps of analysis in the decision making process using the AHP method:
Step 1: Define the decision problem and goal.

Step 2: Structure the hierarchy from the top through the intermediate to the lowest level, which usually contains a list of alternatives.

Step 3: Matrices of pair-wise comparisons are constructed (size $n \times n$ ) for each of the lower levels with one matrix for each element in the level immediately above by using a relative scale measurement.

The decision maker has the option of expressing his or her intensity of preference on a nine-point scale. If two criteria are of equal importance, a value of 1 is given in the comparison, while a 9 indicates an absolute importance of one criterion over the other. The following table shows the measurement scale as defined by Saaty $(1977 ; 1980 ; 1990)$.

Table 1 Measurement scale of AHP

\begin{tabular}{|l|l|}
\hline Intensity of relative importance & Definition \\
\hline 1 & Equal importance \\
\hline 3 & Weak importance of one over the other \\
\hline 5 & Essential or strong importance \\
\hline 7 & Demonstrated importance \\
\hline 9 & Absolute importance \\
\hline
\end{tabular}

Step 4: An eigenvalue is computed according to the relative weights the criteria, and the sum is then taken over all weighted eigenvector entries corresponding to those in the next lower level of the hierarchy.

Step 5: Consistency and consequence weights are analyzed.
The pair-wise comparison data can be analyzed using the eigenvalue technique. Using these pair-wise comparisons, parameters can then be estimated. The right eigenvector of the largest eigenvalue in matrix $A(1)$ constitutes the estimation of the relative importance of the attributes. 
$A=\left(a_{i j}\right)=\mid \begin{array}{ccccc}1 & w_{1} / w_{2} & \cdot & \cdot & w_{1} / w_{n} \\ w_{2} / w_{1} & 1 & & & w_{2} / w_{n} \\ \cdot & & & \cdot & \\ \cdot & \cdot & \cdot & \cdot & \\ & & & & \\ w_{n} / w_{1} & w_{n} / w_{2} & \cdot & \cdots & 1\end{array}$

If matrix $A$ is consistent, that is, if $a_{i j}=a_{i k} a_{k j}$ for all $i, j, k=1,2, \ldots, n$, then $A$ contains no errors (the weights are already known) and we have

$a_{i j}=w_{i} / w_{j}, i, j=1,2, \ldots, n$

Summing up all of $j$, we obtain

$\sum_{i=1}^{n} a_{i, n},-n n_{i .}, 1-1.2 \ldots n$

which, in matrix notation, is equivalent to

$\mathrm{Aw}=\mathrm{nw}$

The vector $\mathrm{w}$ represents the principal right eigenvector of matrix A corresponding to the eigenvalue $n$. If the vector of weights is not known, then it can be estimated from the pair wise comparison of matrix $\hat{A}$ generated by the decision maker by solving for

$A \dot{n}=\lambda \dot{n}$

Matrix $\hat{A}$ contains the pair wise judgments of the decision maker and approximates matrix $A$, whose entries are unknown. In (4), $\lambda$ is an eigenvlaue of $\hat{A}$, and $n$ is the estimated vector of weights. Saaty uses the largest eigenvalue $\lambda_{\max }$ of $\hat{A}$ when solving for

An $\lambda_{s-\mu} n$. 
and has shown that the largest eigenvalue, $\lambda_{\max }$, of a reciprocal matrix $\mathrm{A}$ is always greater than or equal to $\mathbf{n}$ if the pair wise comparisons do not include any inconsistencies, $\lambda_{\max }=\mathbf{n}$. The more consistent the max comparisons are, the closer the value of computed $\lambda_{\max }$ is to n. A consistency index $(\mathrm{Cl})$ that measures the inconsistencies of pairwise comparisons is given in (7).

$\mathrm{CI}=\left(\lambda_{\max }-\mathrm{n}\right) /(\mathrm{n}-1)$

A consistency ratio (CR) is given by (8).

$\mathrm{CR}=100(\mathrm{CI} / \mathrm{RI})$

where $\mathrm{CI}$ is the Consistency Index, $\mathrm{RI}$ is the Random Index, and $\mathrm{n}$ is the number of columns. The RI is the average of the $\mathrm{CI}$ of a large number of randomly generated matrices, where $\mathrm{n}$ is the matrix size. Judgment consistency can be checked by taking the consistency ratio (CR) of CI with the appropriate value in table 2 .

Table 2 Average random consistency (RI)

\begin{tabular}{ccccccccccc}
\hline Size of matrix & 1 & 2 & 3 & 4 & 5 & 6 & 7 & 8 & 9 & 10 \\
\hline Random consistency & 0 & 0 & 0.58 & 0.9 & 1.12 & 1.24 & 1.32 & 1.41 & 1.45 & 1.49 \\
\hline
\end{tabular}

RI depends on the order of the matrix, and a CR of $10 \%$ or less is considered acceptable (Saaty, 1980).

Steps 3-5 are performed for all levels in the hierarchy by using professional commercial software called Expert Choice (Expert Choice, 2004), which simplifies the implementation of the AHP's steps by automating many of its computations. 


\section{Research Design and Data Preparation Research design}

The objective of the present study is to determine a responsibility structure of security jobs based on an evaluation of the factors that influence the job performance of security tasks for each security task conducted at international airports in order to enhance the overall performance of security implementation. The study categorizes airport security tasks into five categories: passenger screening, baggage security control, access control, cargo security, and crisis management for security incidents. It then considers four possible organizations that can take responsibility for these security tasks: the civil aviation authority (Civil Aviation Safety Administration in South Korea), the airport authority, aircraft operators, and the police, all of which are evaluated according to the five factors of accountability to the task, effectiveness of the security activities, efficiency in handling the security processes, cost efficiency, and response to security incidents or disruptive situations. It is necessary to structurize the elements mentioned above in order to utilize the AHP methodology. Table 3 shows the hierarchy structure of the tasks and factors, as well as alternatives to the organizations responsible for various security activities at the airport, and Figure 1 shows the systematic structure of the evaluation.

Table 3 Structural composition of elements for AHP decision model

\begin{tabular}{|c|c|c|}
\hline Level & Categories & Description \\
\hline $\begin{array}{l}\text { level } 1 \\
\text { (goal) }\end{array}$ & \multicolumn{2}{|c|}{$\begin{array}{l}\text { The proper entity takes responsibility for major security tasks at an airport in order to } \\
\text { enhance performance of security activities }\end{array}$} \\
\hline \multirow{5}{*}{$\begin{array}{c}\text { level } 2 \\
\text { (major security } \\
\text { tasks) }\end{array}$} & Passenger screening & $\begin{array}{l}\text { Passenger and carry-on baggage screening by metal detectors and X- } \\
\text { ray machines }\end{array}$ \\
\hline & $\begin{array}{l}\text { Baggage security } \\
\text { control }\end{array}$ & $\begin{array}{l}\text { Security control for checked baggage being loaded at cargo } \\
\text { compartment }\end{array}$ \\
\hline & Access control & Access control to restricted area, building, and aircraft \\
\hline & Cargo security & $\begin{array}{l}\text { Security control for unaccompanied cargo, mail, and other goods } \\
\text { loaded in passenger and cargo planes }\end{array}$ \\
\hline & Crisis management & $\begin{array}{l}\text { Tasks designed to handle emergency situations caused by security } \\
\text { incidents }\end{array}$ \\
\hline \multirow{5}{*}{$\begin{array}{l}\text { level } 3 \\
\text { (evaluation } \\
\text { factors) }\end{array}$} & Accountability & $\begin{array}{l}\text { Recognizing security tasks as its ultimate obligation, and being } \\
\text { accountable }\end{array}$ \\
\hline & $\begin{array}{l}\text { Effectiveness of } \\
\text { security }\end{array}$ & $\begin{array}{l}\text { Job performance; for example, how well they search and detect } \\
\text { weapons, explosives, and dangerous items. }\end{array}$ \\
\hline & $\begin{array}{l}\text { Efficiency in } \\
\text { processing }\end{array}$ & $\begin{array}{l}\text { Efficiency in handling passenger, baggage, and cargo for security } \\
\text { measures, including, for example, efficient decision making } \\
\text { processes, flexibility to adjust to the situation, speed of screening, } \\
\text { etc. }\end{array}$ \\
\hline & Cost efficiency & Costs for the same level of performance of security measurements \\
\hline & \begin{tabular}{|c|}
$\begin{array}{c}\text { Response to security } \\
\text { events }\end{array}$ \\
\end{tabular} & $\begin{array}{l}\text { Ability to respond to irregular and incidental situations during } \\
\text { security implementation }\end{array}$ \\
\hline \multirow{4}{*}{$\begin{array}{l}\text { level } 4 \\
\text { (alternatives) }\end{array}$} & $\begin{array}{c}\begin{array}{c}\text { Civil aviation } \\
\text { authority }\end{array} \\
\end{array}$ & $\begin{array}{l}\text { Government organization responsible for civil aviation, like CASA } \\
\text { in Korea }\end{array}$ \\
\hline & Airport Authority & $\begin{array}{l}\text { Organization responsible for operating the airport, like the Incheon } \\
\text { International Airport Corporation }\end{array}$ \\
\hline & Aircraft Operator & Entities that operate aircraft as their main business, like airlines \\
\hline & Police & $\begin{array}{l}\text { Any police organization which is responsible for law enforcement } \\
\text { concerned with airport security }\end{array}$ \\
\hline
\end{tabular}


Goal Level

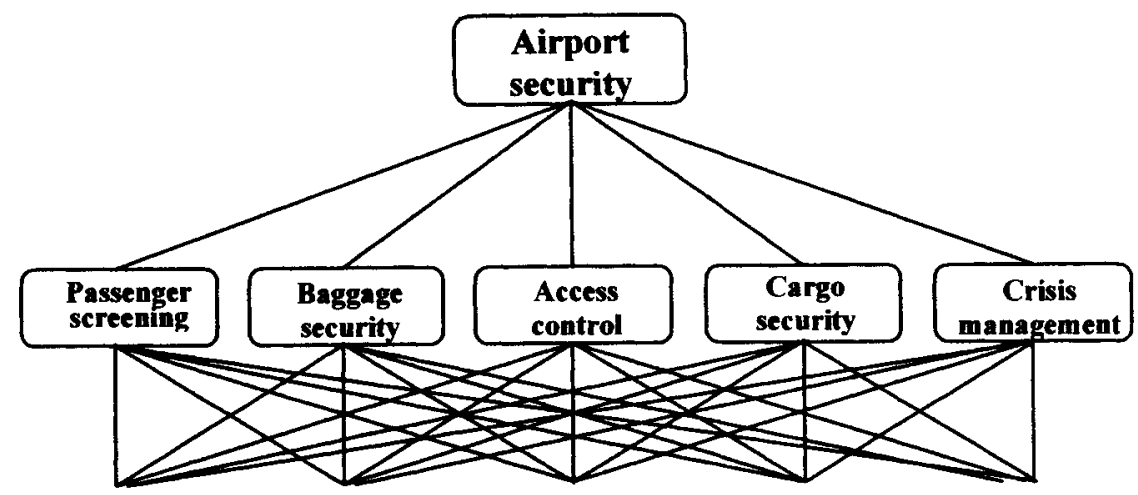

Level 3

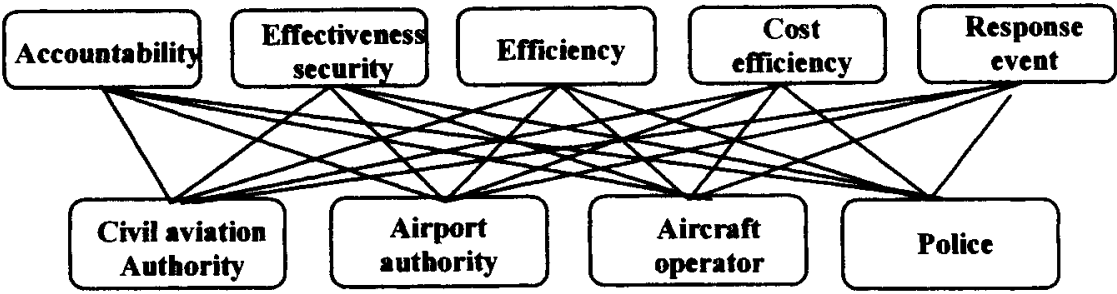

Figure 1. AHP decision model

\section{Data preparation}

A printed questionnaire utilizing the structured elements shown in Table 3 and Figure 1 was prepared as an AHP survey and distributed to security practitioners working at Incheon International Airport who have three or more years experience in aviation security. A total of 45 questionnaires were distributed and 39 responses were collected. Four responses among the 39 collected were eliminated from the analysis because of a lack of consistency. The reliability of the remaining 35 responses was confirmed by a consistency ratio test.

\section{Results of Analysis}

Relative importance of each security task concerning overall security performance at the airport

First, the study evaluated the relative importance of five security tasks: passenger screening, baggage security control, access control, cargo security and crisis management for security incident (refer to Figure 1). Results of the evaluation are present in Figure 2. Passenger screening was pointed out as being the most important task among the five security tasks concerning the enhancement of the performance of airport security activities. The second most important task was checked baggage control. Access control, cargo security, and crisis management were all ranked as less important than passenger and baggage security. These results may reflect respondents' awareness that there have been numerous major security incidents such as hijackings and sabotages caused by the failures of passenger or baggage security control 


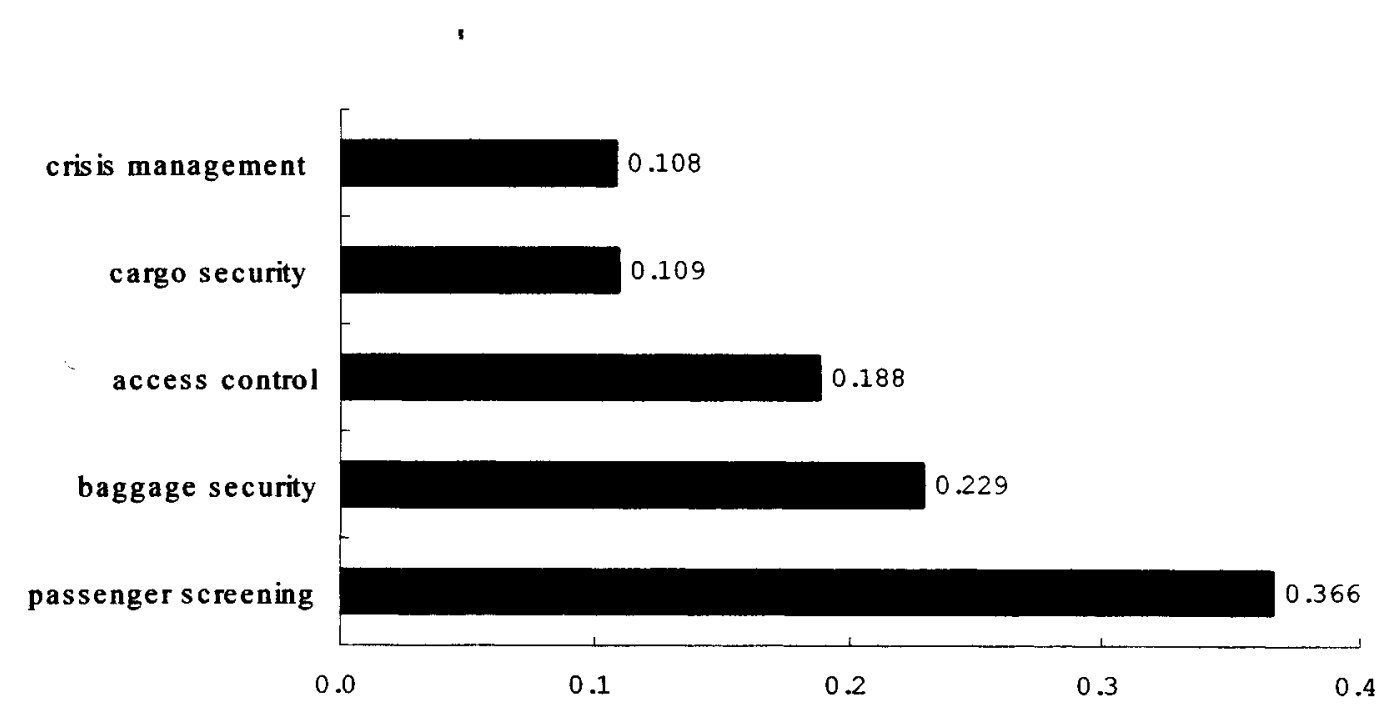

Figure 2. Relative importance of each security task 
Relative importance of each evaluation factor for each security task

The present study tries to weigh the importance of each evaluation factor for each security task. Figure 3 shows the relative importance of each of these factors.

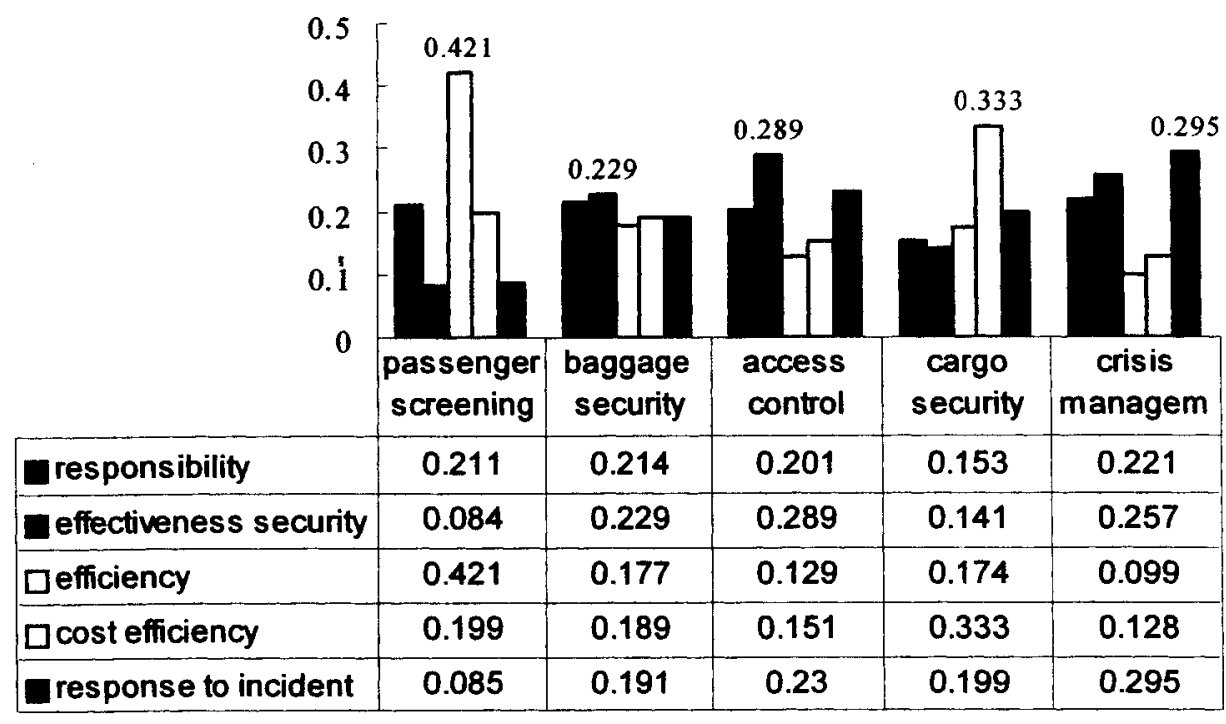

Figure 3. Relative importance of each evaluation factor for each security task

\section{a. Passenger screening task}

For the passenger screening task, the respondents expressed that accountability in the work process is the most important evaluation factor. This is understandable when we consider the long queue in front of the security screening points during peak hours at Incheon International Airport. In such situations, passenger screeners are often pressed for time by the work environment and thus may not conduct screening carefully unless there is a significant amount of accountability attached to this task. It has been reported that there are more than a few cases of disputes between passengers and screeners because of physical contact, delayed processes, or confiscation of prohibited items. Screeners who do not have a serious sense of accountability may allow passengers or their carry-on luggage to go through the screening process without proper inspection, for example when screeners encounter ambiguous situations during peak passenger traffic hours.

Numerous inspectors' tests and observations of passenger screening check points have revealed that many suspicious situations involving passenger and carry-on luggage screenings are being overlooked. Understanding this problem, the respondents pointed out effectiveness of the task as being the second most important factor. The author considers that the practitioners who acutely understand this situation pointed out the problem on the questionnaire.

\section{b. Baggage security control task}

The effectiveness of the security activity ranked as the most important factor for evaluating the baggage security control task. Since the process of baggage screening is not conducted in public, respondents did not emphasize the efficiency or flexibility of situation handling. Instead, they emphasized the effectiveness of the job because they have knowledge of some notorious historical security incidents caused by explosives smuggled in baggage. Accountability was considered the second most important factor for the baggage security control task. This may also be because they are aware of the history of threats concerning explosives contained in baggage.

c. Access control task

The effectiveness of security was reported as the most important factor concerning the access control task, and accountability was considered to be the second most important. The task of access control is to protect restricted areas and involves guarding and patrolling. The surveyed security practitioners considered effectiveness and accountability to be more important than efficiency or ability to respond to incidents.

\section{d. Cargo security task}

Cost efficiency ranked highest for the cargo security task. The handling of cargo is a matter that concerns industry relations, and is not related to the general public. Cargo 
security can be improved through industry activities, utilizing a known consignor system or a regulated agents system. Therefore, neither effectiveness nor accountability of the security service providers at the airport is emphasized here.

\section{e. Crisis management task}

The factors of efficiency and response to security incidents were regarded as the more important factors for the task of crisis management. Crisis management requires flexible and dynamic decision making, which in turn needs task efficiency. It is somewhat natural that the ability to respond to security incidents is emphasized for this task.

\section{Conclusions}

In order to achieve the final goal of the present study, it is necessary to decide who the responsible entity for each security task at the airport should be. This objective can be achieved in two steps. The first step is to find the crucial functional factor for each security task, and the second is to identify the proper entity that can best achieve those crucial factors. The present study has already determined the important functional factors associated with each security task, as mentioned in the previous section. Further, Figure 4 shows the relative capability of each organization concerning achievement of each functional factor of the security activities. According to the figure, the civil aviation authority within the government (Civil Aviation Safety Administration in South Korea) was identified as the most suitable organization when considering the factors of effectiveness of security, accountability, and response to security incidents, while the airport authority was considered the most suitable for the factors of efficiency in handling traffic and cost efficiency.

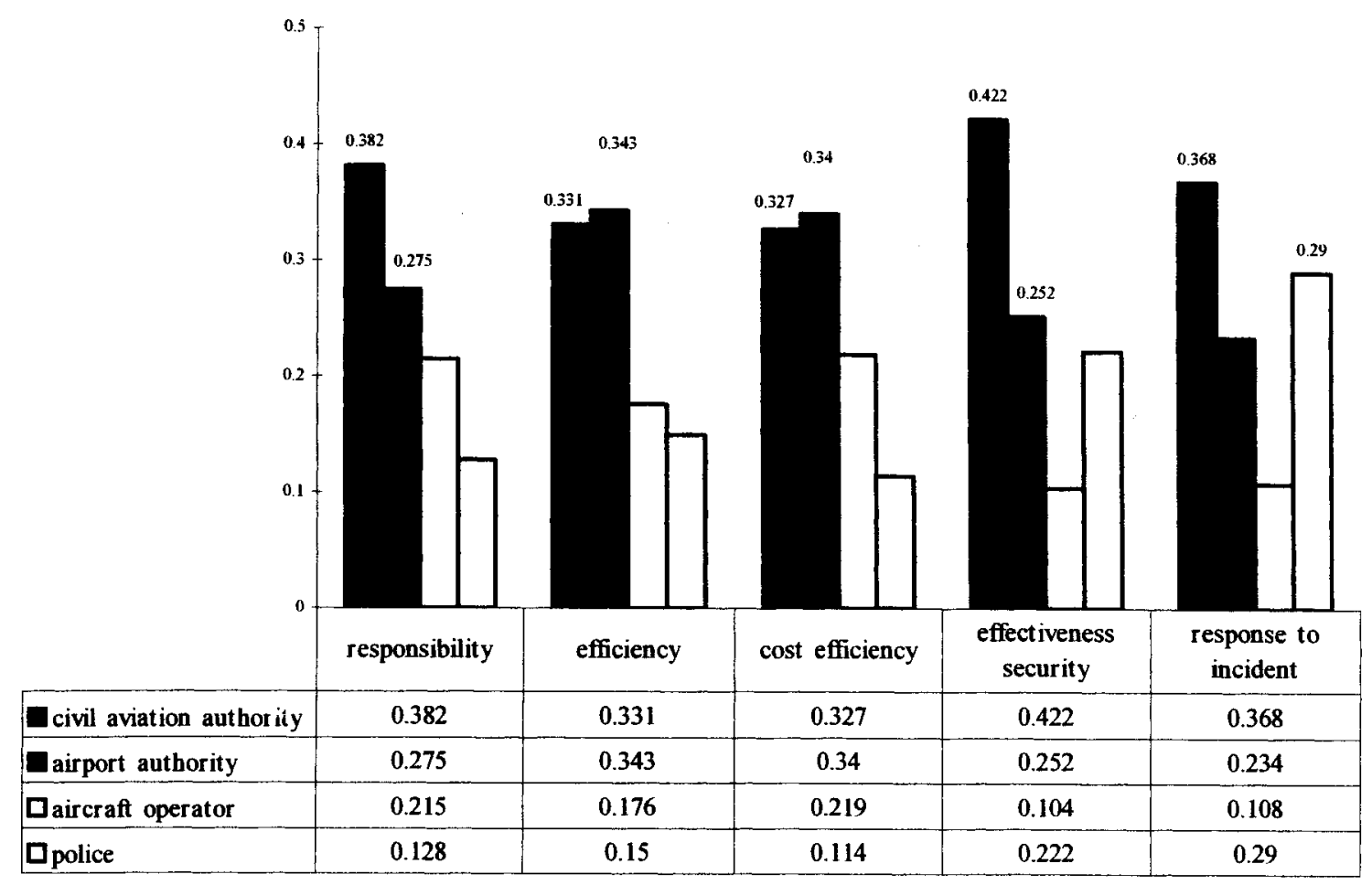

Figure 4. Each entity's capability of handling each factor 
Since the factors of effectiveness of security and accountability were emphasized as important functions for the tasks of passenger screening, checked baggage security control, and access control, the civil aviation authority (Civil Aviation Safety Administration in South Korea) can be finalized as the most suitable organization to take responsibility for these functions. In addition, the civil aviation authority is also the most suitable entity for crisis management tasks because the factors of response to security incidents and effectiveness of security are the most important factors for this task, and the civil aviation authority can handle these factors best.

On the other hand, cargo security control should be the airport authority's responsibility because this task requires the factor of efficiency in handling traffic as its top priority, and the airport authority is considered to be the best organization for the factor of efficiency.

Table 4 responsible authority for each task according to importance of factor

\begin{tabular}{|l|l|l|}
\hline \multicolumn{1}{|c|}{ Task } & \multicolumn{1}{|c|}{ Important factors } & \multicolumn{1}{c|}{ Responsible authority } \\
\hline Passenger screening & Accountability, Effectiveness & Civil Aviation Authority \\
\hline Baggage security control & Accountability, Effectiveness & Civil Aviation Authority \\
\hline Access control & Effectiveness of security & Civil Aviation Authority \\
\hline Cargo security & Cost efficiency & Airport authority \\
\hline Crisis management & Response to security incidents & Civil Aviation Authority \\
\hline
\end{tabular}

Currently, all security tasks except cargo security, which is the airlines' responsibility, are the responsibility of the airport authority at Incheon International Airport. According to the results of the present study, it is desirable to move the responsibility for passenger screening, baggage security, access control, and crisis management from the airport authority to the Civil Aviation Safety Administration. Further, the responsibility of cargo security should be moved from the airlines to the airport authority.

However, we should keep in mind that the present study utilizes opinion data gathered from current practitioners of aviation security activities at the research area only. The study reflects neither the standpoint of customers nor the opinions of outside experts. Quality of service is one of the most important factors in the air transport industry, and security controls are closely related to the quality of air transport service. Air passengers who are sensitive to service quality may show different opinions from those of security practitioners. Expert opinions other than those of the current participants may also be very different. The authors recommend that further studies include the opinions of customers and outside experts. $\rightarrow$

Kwang Eui Yoo is an associate professor of Aviation Planning and Management at Korea Aerospace University in Goyang City Korea. He currently teaches Airport Management, Aviation Security and Air Transport Management. He has worked as A security auditor for the ICAO USAP program. He earned his PhD. degree at Loughborough University in UK and his Master of Business Administration in Aviation at Embry Riddle Aeronautical University in Daytona Beach, Florida. 


\section{References}

Askew, Geoffrey (2004). Who is the Screening Boss? - Does it Really Matter? Avsec World 2004, Conference Proceedings, Vancouver.

Bouma, J., Brouwer, R., van Ek, R. (2000). The use of integrated assessment methods in Dutch water management: a comparison of cost-benefit and multi-criteria analysis. Third International Conference of the European Society for Ecological Economics, Vienna, May 3-6.

Feng, Cheng-Min (2003), "A Review of Aviation Security Organization", The New Challenge of International Transportation Security, edited by Lawrence W. Lan, Institute of Traffic and Transportation, National Chiao Tung University, Taiwan, 73-84

Gessell, L. and Dempsey P. (1997). Airline Management and Strategies for the 21 st Century. Cass Publications.

ICAO (2003). Aviation Security Training Package / Supervisor. ICAO Montreal.

ICAO (2002a). Security Manual. (Doc. 8973/6), ICAO Montreal.

ICAO (2002b). Annex 17 to the Convention on International Civil Aviation. $7^{\text {th }}$ ed., ICAO Montreal.

Korea, MOCT (2002). Act on Aviation Safety and Security, MOCT, Seoul.

Saaty, T.L. (1977). A Scaling Method for Priorities in Hierarchical Structures. Journal of Mathematical Psychology 15, 234-281.

Saaty, T. L. (1980). The Analytic Hierarchy Process. 3rd ed., McGraw-Hill, New York.

Saaty, T. L. (1990). How to Make a Decision: the Analytic Hierarchy Process. European Journal of Operational Research 48, 9-26.

Varis, O. (1989). The Analysis of Preferences in Complex Environmental Judgements a Focus on the Analytic Hierarchy Process. Journal of Environmental Management 28, 283-294.

Yoo, K. and Lee. J. (2004). Airport Security: Establishing a Clear Chain of Command. Avsec World 2004, Conference Proceeding, Vancouver. 
Journal of Aviation/Aerospace Education \& Research, Vol. 19, No. 1 [2009], Art. 1 